\title{
Chamaerops humilis L. var. argentea André date palm seed oil: a potential dietetic plant product
}

\begin{abstract}
Chamaerops humilis L. var. argentea André (C. humilis) date palm seeds are an underutilized source of vegetable oil, and no studies describing their physicochemical characteristics to indicate the potential uses of this seed or seed oil have been reported. The oil content of the seeds is about $10 \%$, mainly composed of oleic acid (38.71\%), l.uric acid (21.27\%), 1.noleic acid $(15.15 \%)$, palmitic acid $(9.96 \%)$, and stearic acid $(7.17 \%)$. The tocol (tocopherols and tocotrienols) content is $74 \mathrm{mg} / 100 \mathrm{~g}$, with $\delta$-tocotrienol as the major contributor $(31.91 \%)$, followed by $\alpha$-tocotrienol (29.37\%), $\gamma$-tocopherol (20.16\%), and $\gamma$-tocotrienol $(11.86 \%)$. Furthermore, this oil shows high thermal stability. The differential scanning calorimetery curves revealed that the melting and crystallization points are $9.33{ }^{\circ} \mathrm{C}$ and $-15.23{ }^{\circ} \mathrm{C}$, respectively. Practical Application: The study revealed that $\mathrm{C}$. humilis seed oil has a great nutritional value. The consumption of this oil, either directly or via many food products, could possibly prevent many diseases, including coronary disease. These findings should make this oil of interest for several food and nonfood applications. C. humilis palms can be easily propagated by seeds. C. humilis dates are a potential source of $1 . \mathrm{w}$-cost seed oil, and the 1.rge-scale cultivation of this crop can yield positive socioeconomic benefits to rural communities wherever date palm tree will grow.
\end{abstract}

Keyword: Chamaerops humilis var. argentea; Dietetic oil; Fatty acids; Seed oil; Tocotrienols 